\title{
Development of an Experimental Near-Real-Time Drought Monitor for India*
}

\author{
REEPAL D. SHAH AND VIMAL Mishra \\ Civil Engineering, and Information Technology Research Academy Water Project: Measurement \\ to Management (M2M), Indian Institute of Technology Gandhinagar, Gujarat, India
}

(Manuscript received 7 March 2014, in final form 21 July 2014)

\begin{abstract}
Persistent and widespread drought hampers water resources management and crop production. India has faced frequent droughts over the last few decades. Despite the detrimental impacts of droughts in India, a real-time monitoring system at appropriate spatial and temporal resolution has been lacking. Here, an experimental drought monitor for India is developed that operates daily at a spatial resolution of $0.25^{\circ}$ and provides near-real-time information on droughts. The real-time daily precipitation data are obtained from the Tropical Rainfall Measurement Mission (TRMM) while daily temperatures are obtained from the Global Ensemble Forecast System (GEFS), version 2. Near-real-time precipitation and temperatures are bias corrected using the historic precipitation and temperature data from the India Meteorological Department (IMD). Data extending from the past to near present were reconstructed by combining IMD (1969-2010) with real-time, bias-corrected TRMM and GEFS datasets (2010 onward). The experimental drought monitor provides information on meteorological, hydrological, and agricultural droughts using the standardized precipitation index (SPI), standardized runoff index (SRI), and standardized soil moisture index (SSI), respectively. Soil moisture and runoff are simulated using the Variable Infiltration Capacity (VIC) model in near-real time to estimate the severity and areal extent of agricultural and hydrological droughts. The severity and areal extent of droughts from the experimental drought monitor are successfully evaluated against a satellite-based drought severity index. The experimental drought monitor provides high-resolution drought information (district level) that can be valuable for natural resources management and policy making.
\end{abstract}

\section{Introduction}

Drought is a natural disaster that affects water resources, crop production, and gross domestic product (GDP). Unlike other natural disasters, it is difficult to identify onset of drought (Smith and Katz 2013). Drought can have large spatial coverage extending up to entire continents, and large temporal coverage lasting multiple years, which makes drought one of the costliest natural disasters (Smith and Katz 2013). Extreme drought for a few continuous months can lead to hazardous conditions

\footnotetext{
* Supplemental information related to this paper is available at the Journals Online website: http://dx.doi.org/10.1175/ JHM-D-14-0041.s1.

Corresponding author address: Vimal Mishra, Assistant Professor, Indian Institute of Technology Gandhinagar, VGEC Campus, Chandkheda, Ahmedabad, Gujarat 382424, India.

E-mail: vmishra@iitgn.ac.in
}

and loss of human lives. For instance, between 1967 and 1991, out of all deaths due to natural disasters, nearly $37 \%$ were caused by droughts (Obasi 1994; Kogan 1997). More than 60 million people were affected in Central and southwestern Asia during the 1999-2000 multiyear droughts (Mishra and Singh 2010; Feyen and Dankers 2009). Moreover, extreme droughts in China during 2010-11 caused substantial migration (FAO 2011). In India, nearly $36 \%$ of districts and $12 \%$ of the total population falls in a rainfall-deficient zone, which makes the region vulnerable to drought. India suffered a loss of 2 billion U.S. dollars while 750 million people were affected because of droughts between 1980 and 2010 (www. preventionweb.net/english/countries/statistics/?cid=79).

Droughts affect the food and water security of a region directly or indirectly. For instance, meteorological droughts lead to soil moisture deficits (Wang et al. 2009), affecting plant growth (Chapin 1991), which in turn hampers the overall quality and quantity of crops produced (Mishra and Cherkauer 2010). Moreover, soil 
moisture depletion below the permanent wilting point results in crop mortality, putting the food security of the region at risk. In China, a noticeable drop in wheat production was noticed (FAO 2011) because of a drought in 2010-11. A drought in 1979 in India led to a $20 \%$ reduction of crop production. Other than food security, hydrological droughts often lead to freshwater insecurity in the affected region. Prolonged meteorological droughts lead to hydrological droughts, which in turn result in reduced flow in streams and rivers (Feyen and Dankers 2009); a lowered water table (Dahm et al. 2003); and depleted lakes, ponds, and reservoirs. For instance, $80 \%$ of the area of the state of Orissa (India) showed depletion in groundwater during the 2002 drought (Panda et al. 2007). Major river basins and parts of India face regular occurrences of droughts, largely driven by erratic monsoon conditions (Bollasina et al. 2011; Mishra et al. 2012).

Detrimental impacts of droughts can be mitigated by proactive planning such as monitoring drought conditions in real time. Real-time monitoring of drought conditions is essential for a country like India to assess the conditions of precipitation, evapotranspiration, soil moisture, runoff, and vegetation health, which can minimize risks to food and water security. Furthermore, monitoring can provide information on the intensity and spatial extent of droughts (Svoboda et al. 2002), which can assist in proactive planning and decision making. Identification of the onset and development of droughts can assist administrators, water managers, and farmers.

Real-time monitoring of drought conditions at appropriate spatial and temporal resolutions is vital. Most of the global drought monitoring systems (AghaKouchak and Nakhjiri 2012; Hao et al. 2014) operate at coarse spatial and temporal resolutions, which may not be sufficient for district-level decision making. Pozzi et al. (2013) identified the potential of setting up a real-time global drought early warning system by combining different regional and national drought systems. Existing drought monitoring systems in India work only during the monsoon season [June-September (JJAS)] and merely provide information on the meteorological conditions (www.imdpune.gov.in). While near-realtime drought monitoring is challenging, remotely sensed data resources (Mu et al. 2013; Huffman et al. 2007) available in real time and land surface hydrologic models (Rodell et al. 2004; Sheffield and Wood 2008a) that can simulate hydrological variables provide a basis for further advancement. Here, we discuss the development of an experimental near-real-time drought monitor for India that works at high spatial and temporal resolutions.

\section{Data and methods}

\section{a. Data}

\section{1) STATION-BASED PRECIPITATION AND TEMPERATURE DATA}

We obtained daily precipitation data at $0.25^{\circ}$ spatial resolution for the period of 1901-2010 developed by the India Meteorological Department (IMD; Niranjan Kumar et al. 2013). The newly gridded precipitation data at high spatial resolution was developed using the 6995 stations located across India (Niranjan Kumar et al. 2013). Niranjan Kumar et al. (2013) reported that in the new gridded precipitation product, climatological and variability features of precipitation are better represented and orographic precipitation in the Western Ghats and northeastern India is effectively captured. The gridded methodology for the precipitation dataset was based on the inverse distance weighting (IDW) method as described in Shepard (1968). Further details on the dataset can be obtained from Niranjan Kumar et al. (2013).

In this analysis, we used daily precipitation data from 1969, which overlaps with the period for which daily air temperature (minimum and maximum) datasets are available through IMD. We obtained $1^{\circ}$ gridded daily maximum and minimum temperature data for the period of 1969-2005 from IMD. The dataset was developed by Srivastava et al. (2009) and is based on 395 observational stations across India. Daily maximum and minimum temperatures were regridded to $0.25^{\circ}$ (which is consistent with the resolution of precipitation) using a lapse rate and digital elevation model (DEM) as described by Maurer et al. (2002). Using precipitation and temperature data, we developed a daily meteorological forcing dataset for India at $0.25^{\circ}$ spatial resolution for the period of 1969-2005.

\section{2) REAL-TIME PRECIPITATION AND TEMPERATURE DATA}

The Tropical Rainfall Measurement Mission (TRMM; Huffman et al. 2007) 3B42RT, version 7 (v7), precipitation data were used to develop daily real-time precipitation forcing. Since gridded precipitation data from IMD are only available through 2010, precipitation from TRMM was used from 2011 onward for real-time monitoring. Observed temperature data are not available in near-real time; therefore, we used daily maximum and minimum temperatures from the National Centers for Environmental Predication (NCEP) Global Ensemble Forecast System (GEFS; Hamill et al. 2013; Kanamitsu 1989) from 2006 onward. The Earth System Research Laboratory's (ESRL) reforecast version 2 
dataset developed historical weather forecasts using the GEFS and provided 21 ensemble members, produced daily from 0000 UTC initial conditions and available from 1984 onward. The horizontal resolution of the dataset is about $50 \mathrm{~km}$, which is available in four-times-daily temporal resolution. Maximum and minimum temperatures obtained from ensemble mean were further regridded to $0.25^{\circ}$ using the high-resolution DEM and methodology described in Maurer et al. (2002). More details about the GEFS products can be obtained from Hamill et al. (2013).

\section{b. Bias correction of real-time precipitation and temperature}

We evaluated bias in real-time precipitation from TRMM (3B42RT v7) and maximum and minimum temperatures obtained from the GEFS. Biases in temperatures and precipitation datasets were estimated against the observed gridded data from IMD. Huffman et al. (2007) found that errors increase in TRMM as resolution becomes finer, which warrants an evaluation of TRMM precipitation data prior to its application for realtime monitoring. Initially, we compared all-India monthly time series of precipitation from TRMM and IMD for the overlapping period of 1998-2007. We compared the number of rainy days (precipitation $>1 \mathrm{~mm}$ ) and total precipitation from TRMM and IMD. We then evaluated TRMM precipitation from extremes [above 90th percentile of IMD precipitation (IMD90), total rainfall due to extremes, and number of extreme rain events] against those from IMD data for the period of 1998-2007.

There have been several approaches for bias correction in satellite precipitation. For instance, Tian et al. (2010) and AghaKouchak and Nakhjiri (2012) used bias correction based on the Bayesian algorithm. On the other hand, Mitra et al. (2009) used the successive correction technique to correct TRMM Multisatellite Precipitation Analysis (TMPA) data using precipitation from the IMD gauge stations. We performed a bias correction of precipitation data from TRMM in two steps: first for precipitation due to extreme events and then for total monthly precipitation. We derived scale factors for extreme events for each monsoon season month for each grid cell by taking a ratio of the mean monthly sum of IMD and TRMM precipitation data above IMD90 for the respective month during the training period (1998-2007). TRMM daily extreme events during the monsoon season months were then corrected by multiplying raw values with their corresponding scaling factors for each grid cell. For extreme precipitation corrections, we only considered the monsoon season, as only a few heavy rainfall events occur in the nonmonsoon season. After correcting TRMM precipitation for extremes in the monsoon season, we derived scale factors for total precipitation for each month by taking the ratio of mean monthly total precipitation from IMD and TRMM. Finally, we corrected daily precipitation data from TRMM by multiplying these two scale factors (extremes and total precipitation) to daily precipitation values.

We evaluated maximum and minimum temperatures from the GEFS for each month for the period of 19842003 (training period) against observed temperatures from IMD. We derived the mean monthly bias in temperatures from GEFS by subtracting IMD's mean daily maximum and minimum temperatures from that of GEFS. We applied bias correction to each grid cell and for each month to correct temperature data in real time. The estimated bias for maximum and minimum temperatures was subtracted from the current GEFS temperatures to obtain bias-corrected daily temperature datasets. We used bias-corrected GEFS temperatures to extend the forcing up to 2010 as daily precipitation from IMD is available until 2010. This resulted in daily meteorological forcings at $0.25^{\circ}$ spatial resolution for the period of 1969-2010. Beyond 2010, the meteorological forcing data were updated based on a bias-corrected (using monthly scale factors to correct daily forcing) dataset from TRMM (for precipitation) and the GEFS (for maximum and minimum temperatures). Daily wind speed data were obtained from the NCEP- National Center for Atmospheric Research (NCAR) reanalysis (Kalnay et al. 1996) and were downscaled at $0.25^{\circ}$ spatial resolution using the methodology described in Maurer et al. (2002).

\section{c. The VIC model}

The Variable Infiltration Capacity (VIC) model (Liang 1994; Liang et al. 1996; Cherkauer et al. 2003) was used to simulate soil moisture and runoff conditions in near-real time using the daily updated meteorological forcing as described in the previous section. Further information on the VIC model and required datasets to run it can be obtained from Gao et al. (2009) and from the Land Surface Hydrology Research Group at the University of Washington (www.hydro.washington.edu). The VIC model can simulate full energy and water fluxes for each grid cell and represents subgrid variability in soil, elevation, and vegetation. The VIC model has been implemented for hydrologic applications ranging from watersheds to global scales (Nijssen et al. 2001; Maurer et al. 2002; Mishra et al. 2010). The model has been widely applied to study soil moisture-based droughts (Sheffield et al. 2004; Andreadis et al. 2005; Andreadis and Lettenmaier 2006; Sheffield and Wood 2008b; 
Mishra and Cherkauer 2010). The VIC model is being used to provide real-time hydrologic information on many platforms: the Experimental Surface Water Monitor at the University of Washington (www. hydro.washington.edu/forecast/monitor/index.shtml), the Drought Monitoring and Hydrologic Forecasting with VIC system at Princeton University (http://hydrology. princeton.edu/forecast/current.php), and the African Flood and Drought Monitor (http://stream.princeton. edu/AWCM/WEBPAGE/interface.php?locale=en).

We used the VIC model, version 4.1.2, in water balance mode to simulate hydrological variables in India. The vegetation parameters based on the 1-km Advanced Very High Resolution Radiometer (AVHRR) global land cover information (Hansen et al. 2000) were obtained from Kumar et al. (2006). Soil parameters were developed using the Harmonized World Soil Database (HWSD), version 1.2, and the methods available on the VIC model website (www.hydro.washington.edu). Since the model spinup may influence output of hydrological variables, we initialize the VIC model using a simulation for the entire period (i.e., 1969-2005). To do this, we first ran the model for the period of 1969-2005 and generated an initial state file at the end of simulation. The same initial state file was used to run the VIC model again from the beginning (e.g., 1 January 1969). However, based on our experience, the VIC model needs a spinup period of about 2 years in the water balance model. We did not calibrate soil moisture simulations from the VIC model; rather, we compared monthly streamflow from the VIC model against the observed for the two basins, Ganges and Mahanadi (see Fig. 1 in the supplemental materials). We find a good agreement between model-simulated and observed streamflow for both watersheds. Moreover, monthly anomalies of the VIC model-simulated soil moisture showed an all-India median correlation of 0.88 with the Noah soil moisture product obtained from the Global Land Data Assimilation System (GLDAS). Areal extents of drought based on standardized soil moisture index (SSI) estimated using the Noah- and VIC model-simulated soil moisture were in good agreement (see Fig. 2 in the supplemental materials). Soil moisture from the VIC model even without calibration has been found reliable for drought studies (Sheffield and Wood 2008b; Mishra and Cherkauer 2010; Mishra et al. 2010, 2014; Wang et al. 2011). Moreover, drought assessment is based on anomalies of soil moisture rather than absolute values; therefore, the model calibration may not be essential for drought studies. However, we evaluated skills of the VIC model for drought monitoring in India against remotely sensed datasets.

\section{d. Characterization of drought: Drought indices}

The experimental drought monitor provides information on meteorological drought, hydrological drought, and agricultural drought in near-real time. We used the standardized precipitation index (SPI; McKee et al. 1993), SSI (Hao and AghaKouchak 2013), and standardized runoff index (SRI; Shukla and Wood 2008) to capture meteorological, agricultural, and hydrological droughts, respectively. SPI, SSI, and SRI are dimensionless and based on the probability distribution of precipitation, soil moisture, and total runoff (surface runoff plus base flow), respectively. We estimated all the drought indices using a parametric (Gamma) distribution. SPI and SRI were estimated at different time scales ranging from 1 to 24 months to provide information on short- and long-term droughts. However, we present the analysis based on 1-month SPI, SRI, and SSI. We estimated SSI using soil moisture for the top $60-\mathrm{cm}$ depth (SM-60). We selected the top $60 \mathrm{~cm}$ to estimate soil moisture-based drought because, for many crops, effective root zone depth falls in this region (Jalota and Arora 2002). Categorization of drought (from moderate to exceptional) was based on the ranges provided by Svoboda et al. (2002).

\section{Results and discussion}

\section{a. Evaluation of TRMM precipitation}

We compared the mean number of rainy days (precipitation $>1 \mathrm{~mm}$ ) and total precipitation during the monsoon season (JJAS) for the training period (19982007; Fig. 1). Observed precipitation from IMD showed that the number of rainy days varied between 0 and 120 , with higher values in the western coast and in northeastern and central India, and a lower number of rainy days in semiarid western India (Fig. 1a). Mean monsoon season precipitation in IMD data varied between 0 and $2200 \mathrm{~mm}$, with higher totals in the Western Ghats and northeastern India and lower precipitation totals in western India (Fig. 1d). The total number of rainy days were underestimated in TRMM (Fig. 1c), while total precipitation during the monsoon season showed mixed patterns-underestimation in the Western Ghats and overestimation in the northeastern region (Fig. 1f). Satellites may tend to underestimate precipitation in coastal areas and regions of complex topography, which results in a dry bias in the Western Ghats. The all-India mean number of rainy days was largely underestimated during the monsoon season in TRMM, while TRMM showed overestimation in all-India total precipitation, especially during the monsoon season (Figs. 1g,h). This suggests that TRMM overestimates 

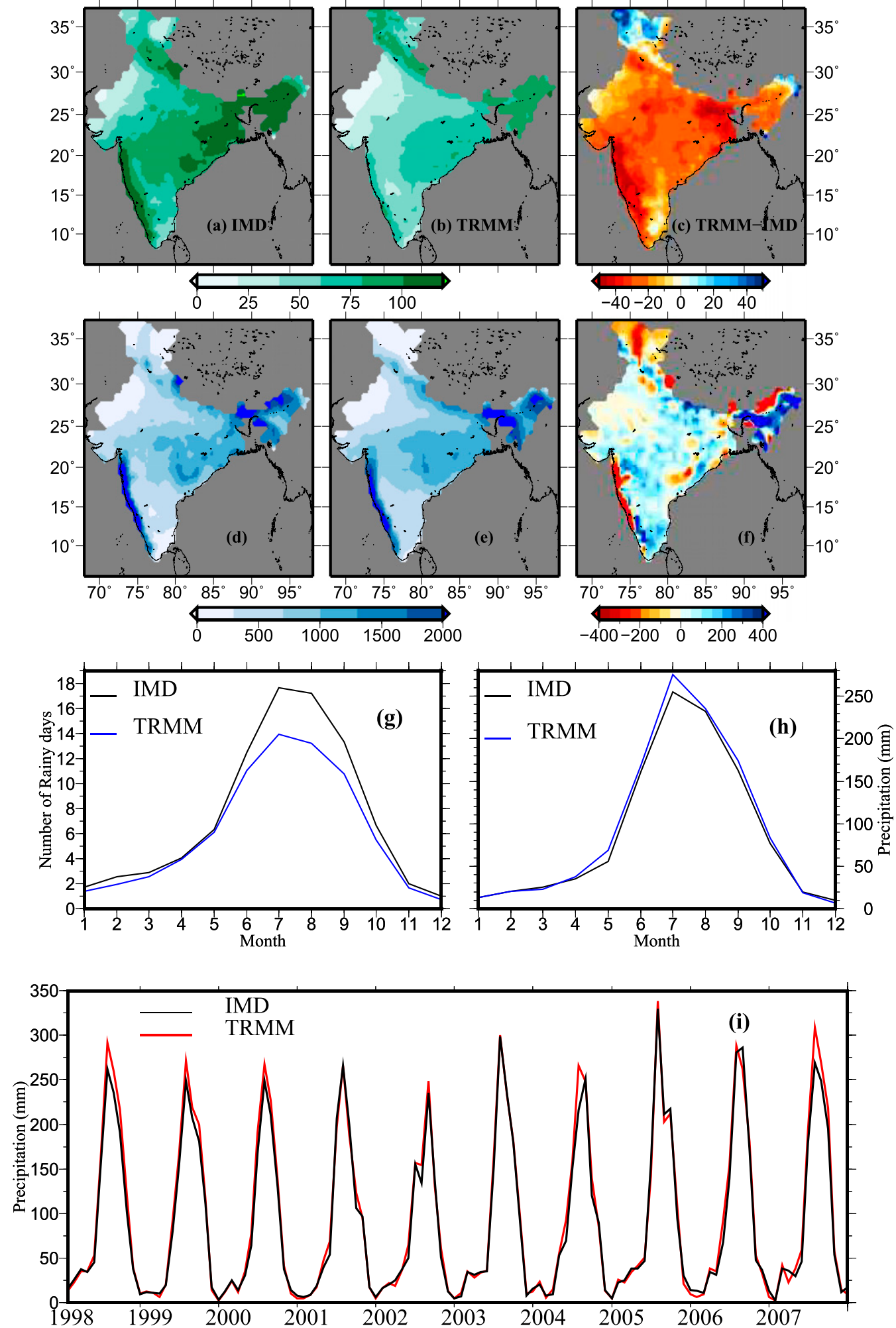

FIG. 1. A comparison of the number of rainy days (precipitation $>1 \mathrm{~mm}$ ) and total precipitation from TRMM with those from IMD. The mean number of rainy days during the monsoon season (JJAS; 1998-2007) from (a) IMD and (b) TRMM, and the (c) bias in the mean number of rainy days in TRMM from IMD. The mean rainfall $(\mathrm{mm})$ in the monsoon season from (d) IMD and (e) TRMM, and the (f) bias (mm) for mean rainfall. The mean monthly (g) rainy days and $(\mathrm{h})$ total rainfall $(\mathrm{mm})$ from IMD and TRMM. (i) The monthly time series of precipitation (mm) from IMD and TRMM during 1998-2007. 
extreme precipitation. However, all-India-averaged monthly precipitation from TRMM captured temporal variability well, as shown in Fig. 1 i.

We evaluated extreme precipitation in TRMM against IMD for the training period (1998-2007; Fig. 2). Extreme precipitation events from TRMM (IMD90) were compared with extreme events from IMD (above IMD90). Extreme precipitation from IMD exhibited typical patterns associated with the Indian monsoonhigh precipitation in the Western Ghats and northeastern region (Mishra et al. 2012) and lower precipitation in semiarid western India (Figs. 2a,b). The average number of extreme precipitation events during the monsoon season varied between 0 and 30 in the IMD dataset and were largely overestimated by TRMM, especially in northeastern and east-central India (parts of western Bengal) and in southern peninsular India (Fig. 2c). However, TRMM underestimated the number of extreme precipitation events in Jammu and Kashmir as well as northern mountains of the northeastern region (Fig. 2e). Similar spatial patterns were observed for total precipitation contributed by extreme events (Figs. 2b,d,f). Furthermore, TRMM showed substantial overestimation in all-India-averaged numbers of extreme events and total precipitation contributed by extreme events throughout year (Figs. $2 \mathrm{~g}, \mathrm{~h}$ ). These results are consistent with the findings of $\mathrm{Su}$ et al. (2008), who reported that extreme events were overestimated by TRMM (3B42 v6) for the La Plata basin. Zhang et al. (2013) found that TRMM showed a dry bias in mountainous regions and a wet bias in plain regions, which is in agreement with our findings. A dry bias in mountainous regions is because satellites tend to miss increments in precipitation over a complex topography (Andermann et al. 2011; Sorooshian et al. 2011; www. disc.sci.gsfc.nasa.gov). Nesbitt and Anders (2009) found that finer-resolution products from TRMM were unable to resolve precipitation gradients in regions such as the Western Ghats and the Himalayas. Huang et al. (2013) found that spatial patterns of 3B42RT are highly correlated with the cloud-top temperature, which may be attributed to the regional bias in extreme precipitation. Moreover, quantitative precipitation estimation (QPE) products (3B42RT), estimated using an algorithm that relates reflectivity with precipitation, do not perform well during extreme events at fine resolution (Huang et al. 2013) and may be associated with overestimation of extreme precipitation, as shown in our results. Mehran and AghaKouchak (2014) and AghaKouchak et al. (2011) found that real-time TMPA (TMPA-RT) has a lower probability of detecting extreme events than stage-4 radar-based, gauge-adjusted data for the United States.

\section{b. Evaluation of bias-corrected TRMM precipitation}

Figure 3 shows the performance of the bias-correction approach for the training (1998-2007) and testing (2008 10) periods. We applied the bias correction in two steps (as described in section $2 b$ ): first for the extreme precipitation and then for total precipitation on a daily basis using monthly scale factors that were obtained for the training period. During the monsoon season, TRMM precipitation showed a large wet and dry bias located in northern and northeastern India and the Western Ghats (Fig. 3a). Figures $3 b$ and $3 c$ demonstrate that the bias was completely removed after applying the corrections based on monthly scale factors for the training period. This is obvious as the monthly scale factors were estimated for the training period. Using the same scale factors (developed for the training period) for the testing period (2008-10), a substantial reduction in bias in precipitation from TRMM was noticed over most of India (Figs. 3d,e). During the testing period (2008-10), the median bias across India improved from 91.86 to 34.44 and from 15.23 to $0.93 \mathrm{~mm}$ during the monsoon and nonmonsoon seasons, respectively. In the training period, the all-India median root-mean-square error (RMSE) improved from 16.92 to 15.65 and from 4.56 to $4.20 \mathrm{~mm}$ during the monsoon and nonmonsoon seasons, respectively. Similar improvements in RMSE were noticed for the testing period. We observed less improvement in RMSE but substantial improvement in bias, which indicates randomness associated with bias in TRMM precipitation. This can be further observed in magnitudes of bias during the training and testing periods (Figs. 3c,f). The availability of TRMM data for longer durations that can be used for training and testing periods may lead to further improvements in bias as the scale factors developed from 8 years of data may not be able to capture a significant portion of variability. This randomness in bias observed for the training and testing periods may be associated with uncertainty in satellite-based precipitation. Uncertainty in satellite-based precipitation may arise because of the type of precipitation, its season, and its topography (Tian and Peters-Lidard 2010; Andermann et al. 2011). AghaKouchak et al. (2012) reported that satellite data show systematic errors that are proportional to the rate of precipitation. Moreover, Zhao and Yatagai (2013) reported that satellite-based precipitation captured observed patterns but failed to reproduce the correct magnitude and timing of precipitation at synoptic and subsynoptic scales. They found that the satellite overestimates heavy precipitation and underestimates light precipitation in China, which is consistent with our findings. 

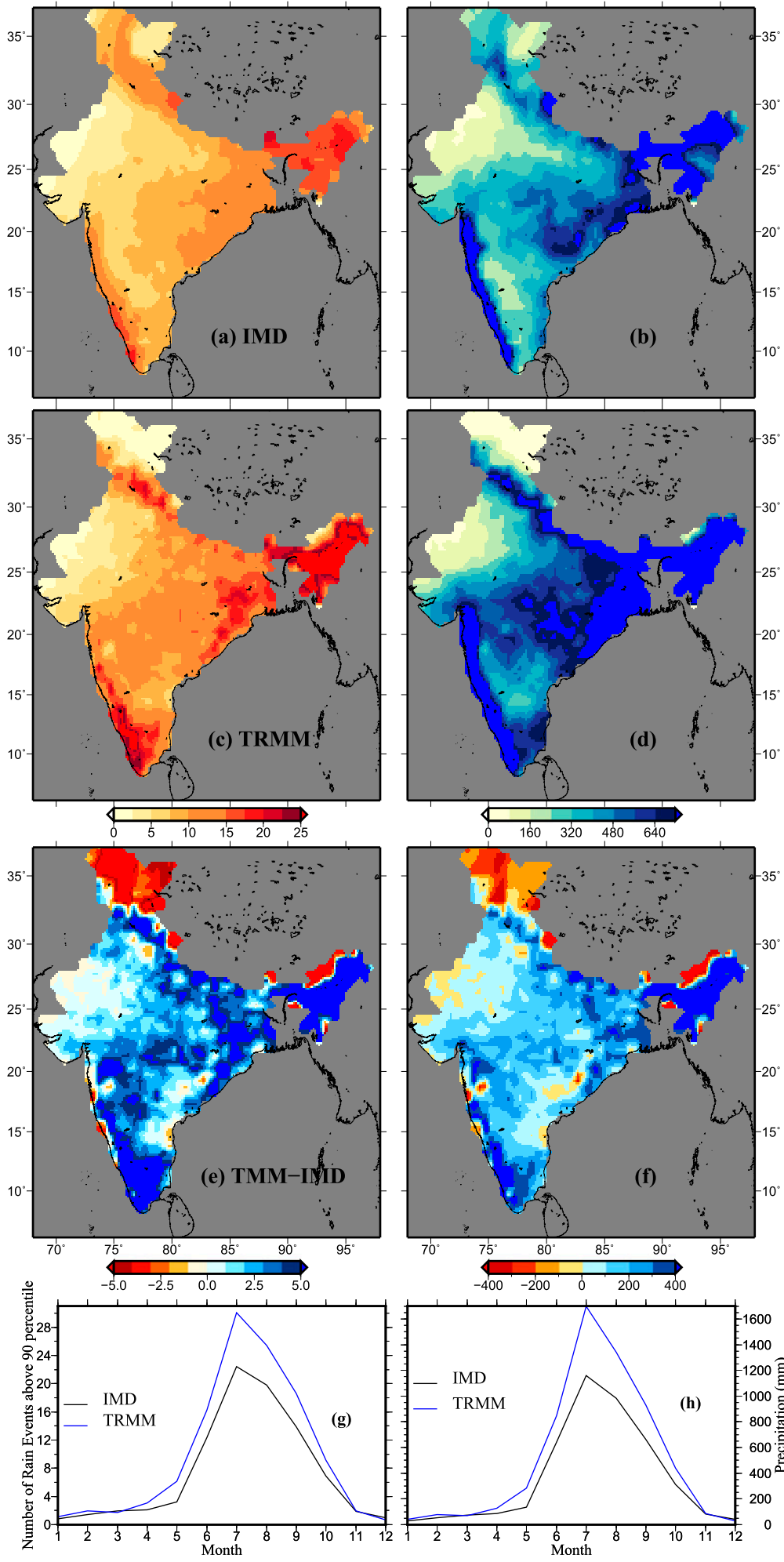

FIG. 2. The number of extreme events [rainfall greater than 90th percentile of IMD rainfall (values $>1 \mathrm{~mm}$ ) for the period of 1998-2007] and the total precipitation due to extreme events. The mean number of extreme events from (a) IMD and (c) TRMM, and the (e) bias in the number of extreme precipitation events. The mean total precipitation due to extreme precipitation events from (b) IMD and (d) TRMM, and the (f) bias in total precipitation due to extreme events. (g) The mean monthly number of extreme events. (h) The precipitation total $(\mathrm{mm})$ due to extremes. 

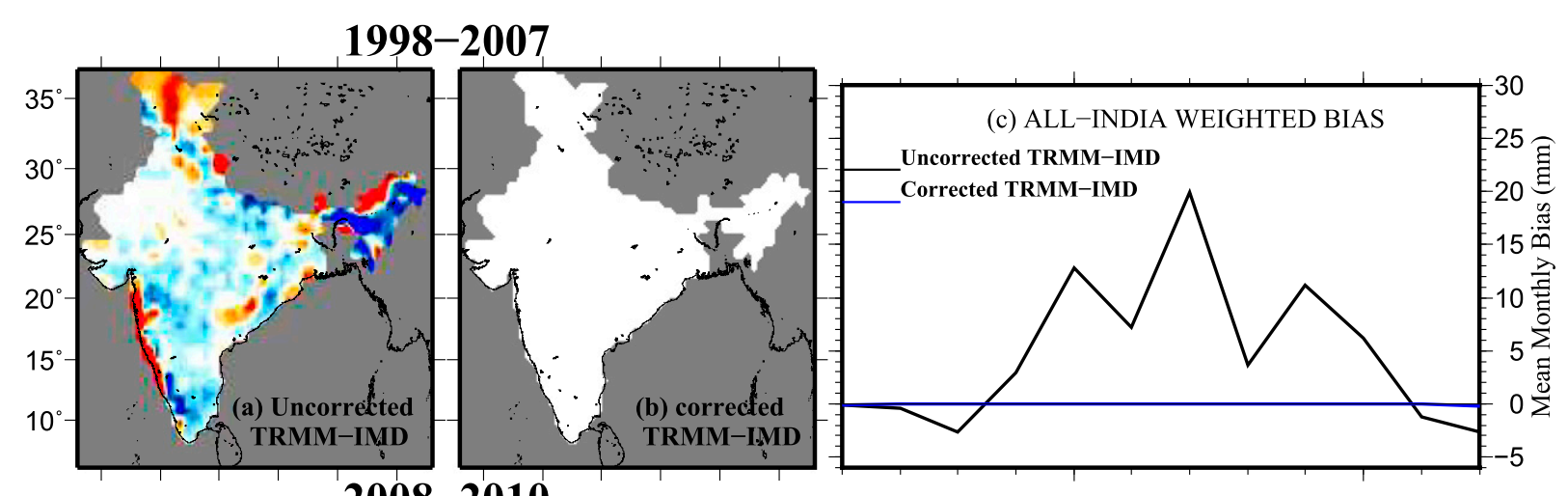

2008-2010
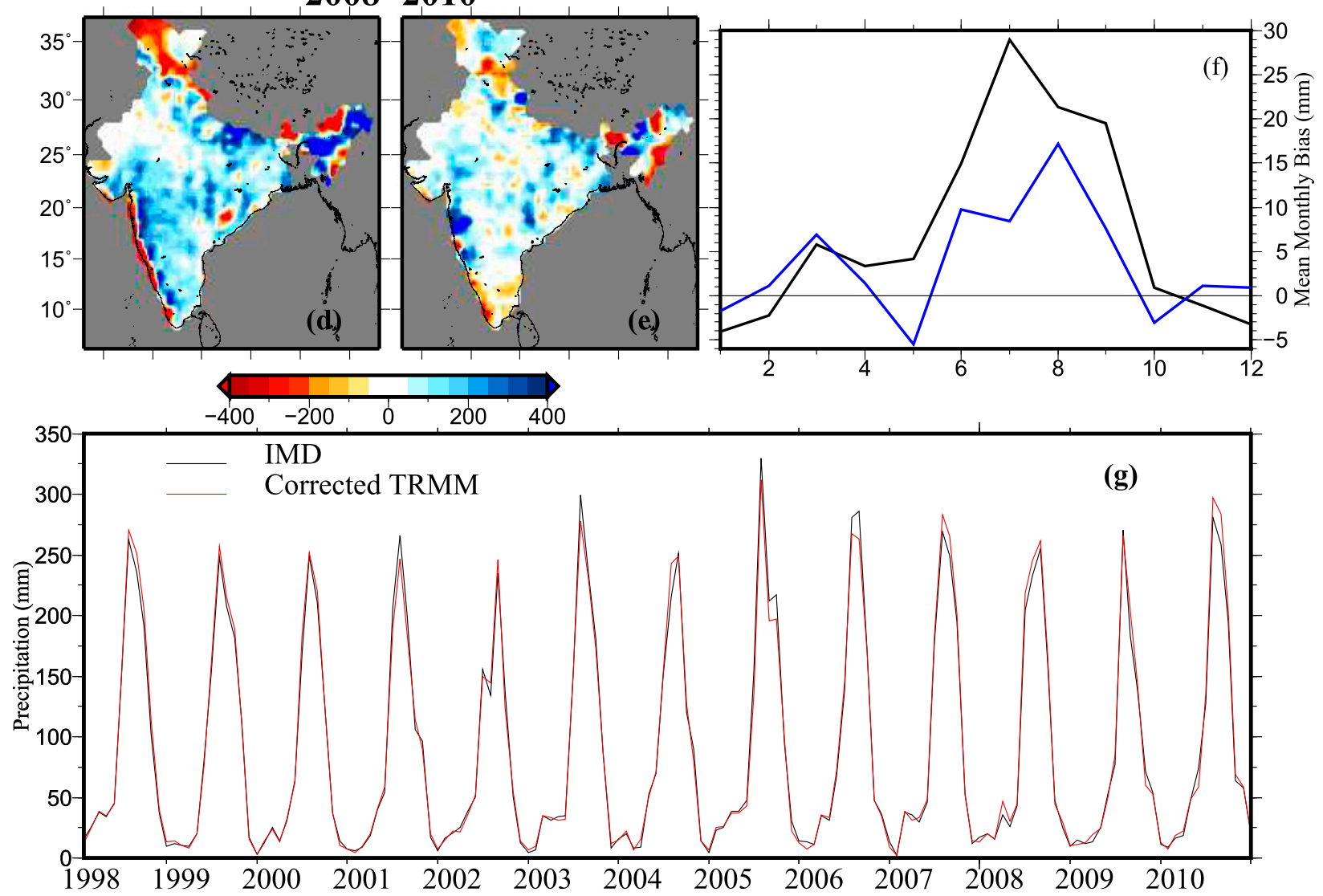

FIG. 3. A comparison of bias in uncorrected and bias-corrected (corrected) TRMM precipitation data. The bias in (a) uncorrected and (b) corrected TRMM during the monsoon season (JJAS) for the training period (1998-2007); (d),(e) the bias in TRMM precipitation for the testing period (2008-10); the mean monthly bias for uncorrected and corrected TRMM during (c) 1998-2007 and (f) 2008-10; and (g) a comparison of bias-corrected monthly precipitation from TRMM against IMD.

\section{c. Evaluation of bias-corrected GEFS temperature}

The GEFS 2-m maximum and minimum temperatures were evaluated against IMD for the common period of 1984-2003 (Fig. 4). GEFS showed a high cold bias in the Himalayan region during the monsoon (JJAS) and nonmonsoon seasons (Figs. 4e-h), while a warm bias in minimum and maximum temperatures was noticed across north-central India, with prominent values in northwestern India during the monsoon season (Figs. 4e,f). On the other hand, for the nonmonsoon season, a cold bias in maximum temperature was found on the eastern coast (Fig. 4h). Gridded daily temperature data from IMD were based on 395 stations across India, and the station density in the complex terrains may even be lower, causing uncertainty in the observations. The Climate Forecast System Reanalysis (CFSR) dataset was used as the initial condition 


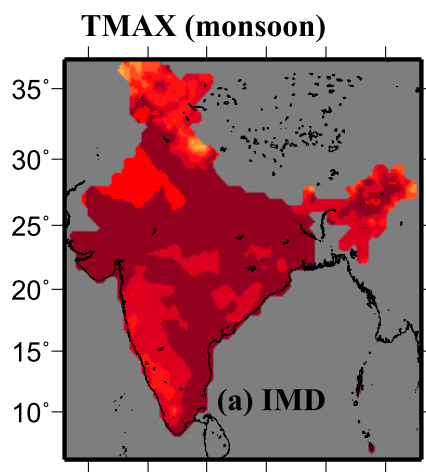

TMIN (monsoon)
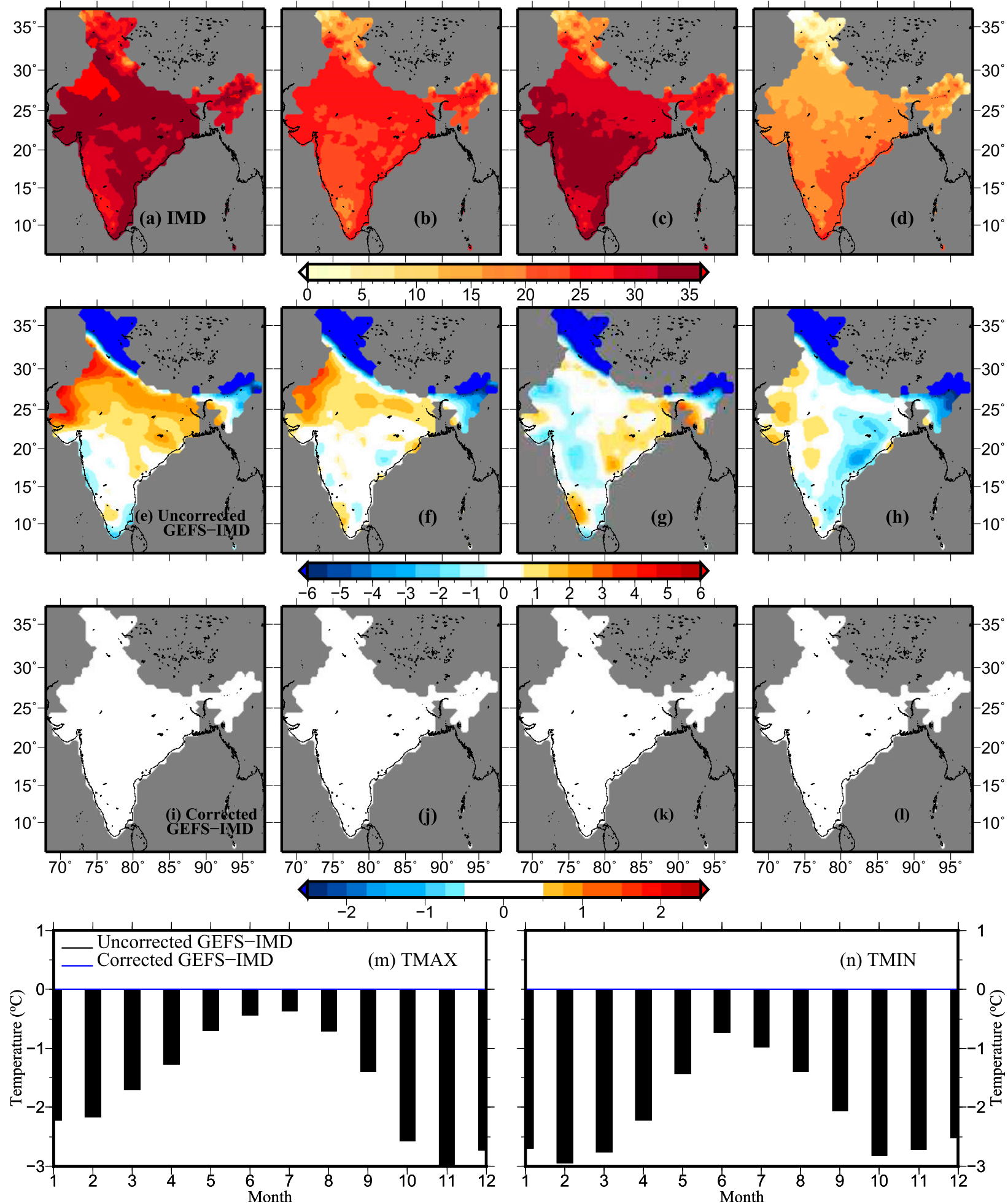

FIG. 4. The mean max and min temperatures $\left({ }^{\circ} \mathrm{C}\right)$ from IMD for the (a),(b) monsoon season (JJAS) and (c),(d) nonmonsoon season during 1985-2003. (e)-(h) The uncorrected bias in max and min temperatures during the monsoon season in the GEFS dataset; (i)-(l) the corrected bias in min and max temperatures for the training period (1985-2003); and (m),(n) the seasonal cycle of uncorrected and corrected bias in max and min temperatures. 
for the GEFS reforecast, version 2 (see Hamill et al. 2013), and some of these uncertainties may be due to inherent bias in initial conditions (Shah and Mishra 2014). For both minimum and maximum temperatures, the all-India-averaged bias is higher during the winter (October-February) season than that of the monsoon season (Figs. 4m,n). Most of the all-Indiaaveraged bias is attributed to a cold bias present in the northern regions. However, after the bias correction, a significant reduction in bias was noticed during the training period (Figs. $4 \mathrm{i}-\mathrm{m}$ ).

We evaluated the bias-correction approach for minimum and maximum temperatures for the testing period (2004-05) as observed temperature data from IMD are available until 2005. Similar spatial patterns were found in the bias in maximum and minimum temperatures for the monsoon and nonmonsoon seasons (Figs. 5e-h). After applying the bias correction, the bias was significantly improved across India; however, a high warm bias was noticed in the Jammu and Kashmir regions in minimum temperature (Figs. 5j,1).

\section{d. Effect of bias correction on soil moisture simulations}

We evaluated SM-60 simulated using uncorrected and bias-corrected meteorological forcing (precipitation and temperature) with that simulated using IMD for the period of 1998-2005 (Fig. 6). This was done to assess the effectiveness of bias correction in soil moisture simulations using the VIC model in near-real time. We regressed monthly SM-60 from IMD forcing on to those obtained with and without bias-corrected forcings based on TRMM and GFES. We find that SM-60 was slightly improved with the bias-corrected forcings, with an all-India median coefficient of determination $R^{2}$ of 0.89 versus 0.87 (Figs. 6a,b). Moreover, we see substantial improvements in SM-60 simulations with bias-corrected forcing in Jammu and Kashmir and the southern peninsula (Fig. 6a), which could be attributed to improvements in temperature bias. For instance, SM-60 simulations are affected by the high cold bias present in the GEFS temperatures in Jammu and Kashmir, which was significantly improved after the bias correction. Moreover, we notice that the seasonal cycle of SM-60 was well captured by the bias-corrected SM-60 (Fig. 6c). All-India median bias in the monthly seasonal cycle of SM-60 estimated using uncorrected forcings improved from 7 to $3 \mathrm{~mm}$ during the monsoon season with biascorrected forcings. However, even after the bias correction, some bias can be seen in the seasonal cycle of SM-60, which can be attributed to bias present in TRMM precipitation, as discussed in the previous sections. All-India-averaged monthly SM-60 demonstrated improved simulations of SM-60 after bias correction (Fig. 6d). Median bias in SM-60 simulated using uncorrected forcing reduced from 6.93 to 3.51 and from 3.95 to $1.83 \mathrm{~mm}$ after bias correction for the monsoon and nonmonsoon seasons, respectively. One may notice a large bias for multiple months in soil moisture anomalies (Fig. 6e), which can be attributed to high persistence in soil moisture in the both corrected and uncorrected simulations.

\section{e. Evaluation of bias-correction approach for drought monitoring}

We compared the areal extent of droughts based on SSI estimated using SM-60 simulated with and without bias-corrected forcing against SSI simulated using the IMD forcing for the monsoon season drought in 2002 (Fig. 7). We notice that SM-60 without bias-corrected forcings overestimated wet areas and underestimated dry areas (in the southern peninsula and central and northern India) during June 2002 (Figs. 7a,b), which can be attributed to the effect of wet bias on the persistence of soil moisture. The overestimation in wet areas, which was present without bias-corrected SM-60, was significantly improved after the bias correction (Fig. 7c). Furthermore, areas under drought as well as in normal conditions were better captured after the bias correction. Significant improvements were noticed to simulate drought extent in the July-September period after using the bias-corrected forcings. For instance, drought extents in northwestern India and the southern peninsula were well simulated after the TRMM precipitation and GEFS temperatures were bias corrected using the observations from IMD (Figs. 7g-1). After the bias correction, the spatial correlation between SSI simulated using uncorrected data and IMD forcing improved from 0.27 to $0.40,0.61$ to $0.72,0.59$ to 0.71 , and 0.57 to 0.69 for June, July, August, and September, respectively. These results further highlight the ability of meteorological forcings based on TRMM and GEFS, which are independent of IMD, to simulate drought extents in nearreal time.

\section{f. Comparisons with satellite-based drought index}

We compared meteorological, hydrological, and agricultural droughts for the monsoon season of 2002 (Fig. 8). At the end of July 2002, widespread meteorological, hydrological, and agricultural drought was found across India, except in northeastern India (Figs. 8b,f,j). During August and September 2002, all types of droughts showed recovery in the majority of India except regions in northwestern India and the southern peninsula (Figs. 8b-d, f-h, j-l). Differences in hydrological 


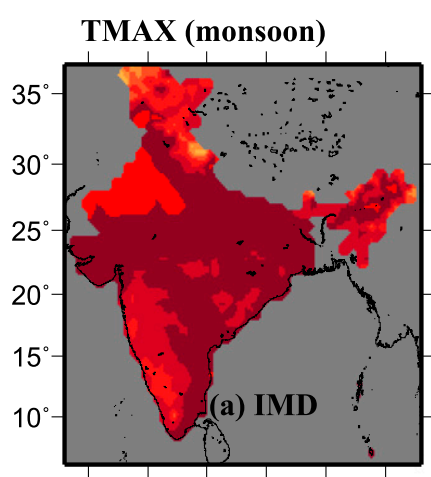

TMIN (monsoon)
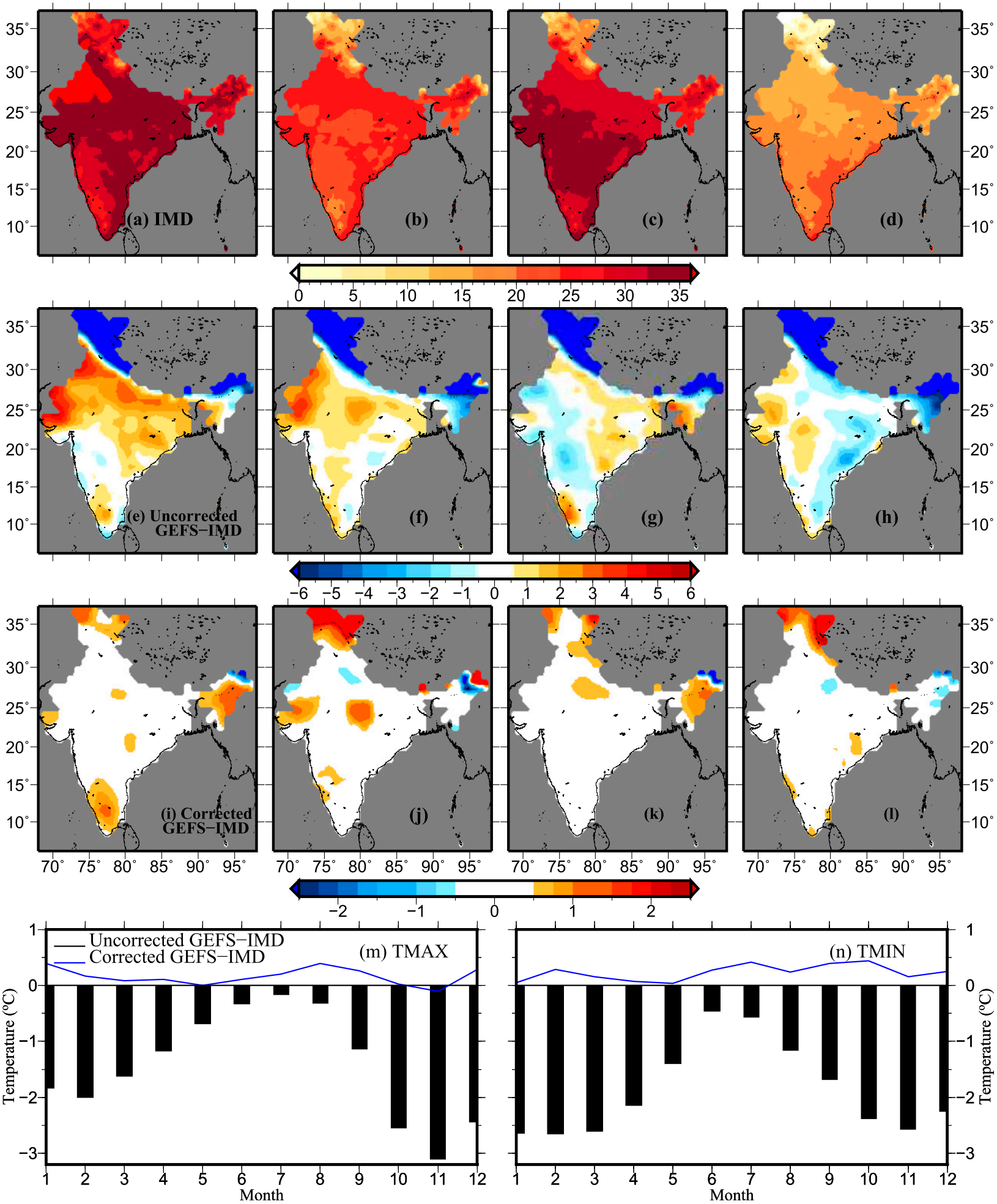

FIG. 5. As in Fig. 4, but for the testing period (2004-05).

TMAX (non-monsoon)

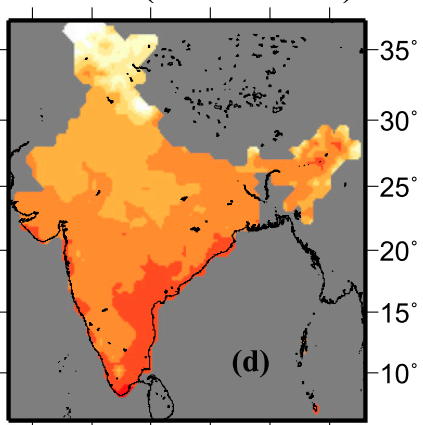

$35^{\circ}$ $0^{\circ}$ $25^{\circ}$ $0^{\circ}$ 

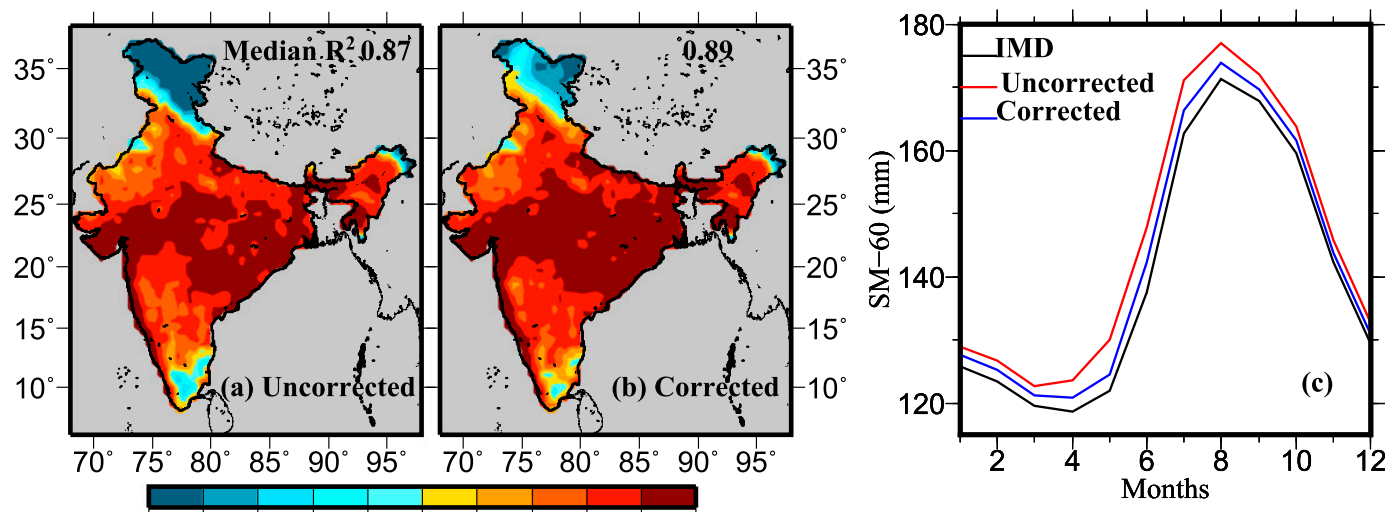

$\begin{array}{lllllllllllll}0.0 & 0.1 & 0.2 & 0.3 & 0.4 & 0.5 & 0.6 & 0.7 & 0.8 & 0.9 & 1.0\end{array}$
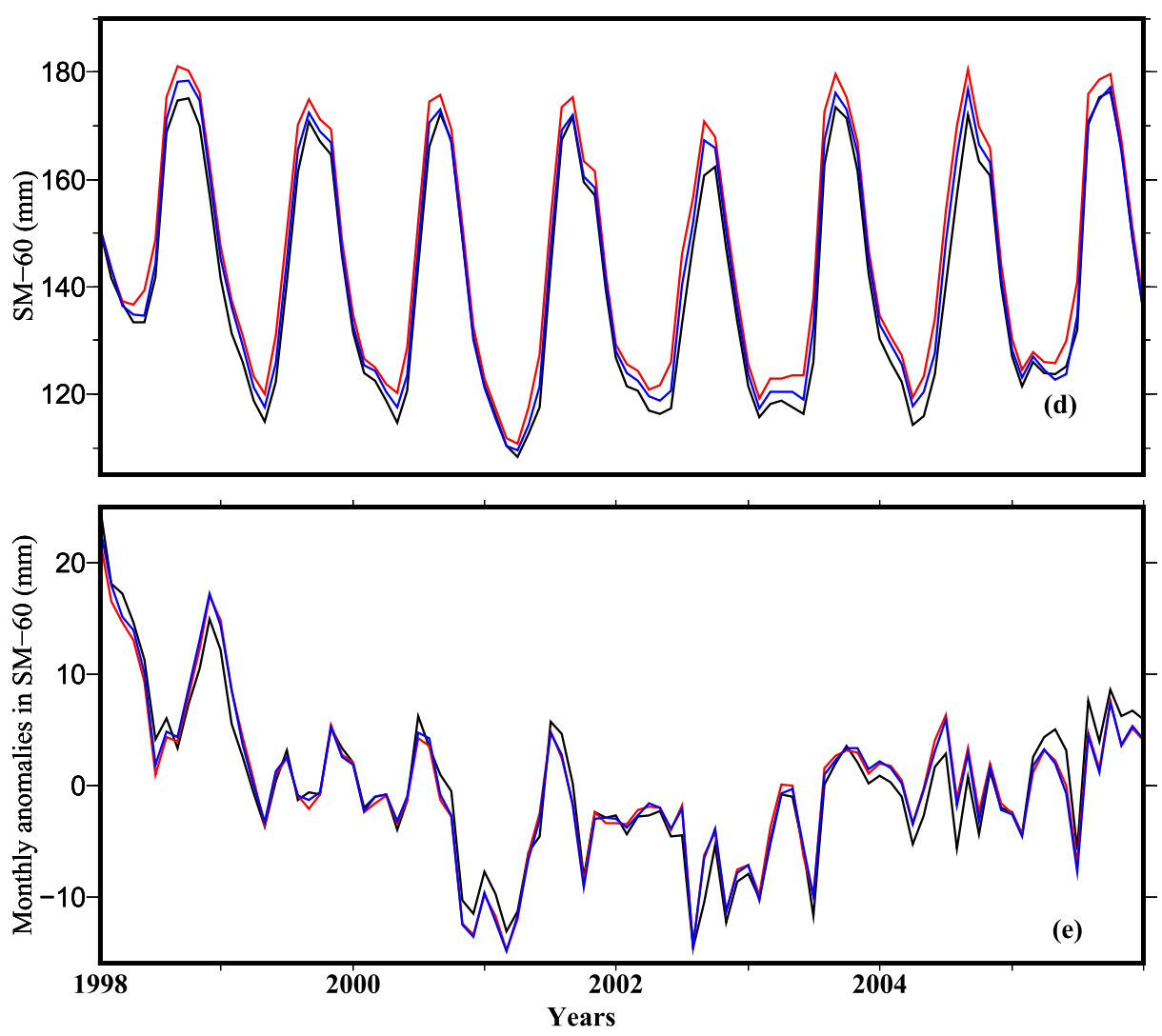

FIG. 6. Comparison of SM-60 simulated using uncorrected and bias-corrected TRMM and GEFS forcings against soil moisture simulated using observed forcing from IMD for 1998-2005. Shown is (a) $R^{2}$ estimated between SM-60 simulated using uncorrected forcing and observed forcing from IMD; (b) $R^{2}$ estimated between corrected forcing and observed forcing from IMD; and (c) seasonal cycle, (d) monthly soil moisture, and (e) monthly anomalies of SM-60.

and agricultural droughts in July 2002 can be mainly attributed to persistence associated with total runoff and soil moisture, respectively.

We compared the VIC model-simulated drought extents for the 2002 monsoon season with the remotely sensed drought extent based on the drought severity index (DSI; Mu et al. 2013) (Figs. 8m-p), which is based on the health of vegetation. Areal extents of severe, moderate, and extreme droughts were compared for the monsoon season of 2002. We find that for all four months, the VIC model-simulated areal extents compared well to those obtained using DSI (Fig. 8). Moreover, drought extents based on SSI (Fig. 8k) are more comparable to DSI, which demonstrate the usefulness of soil moisture-based drought indicators. Disparities in the areal extent of drought in September could be 

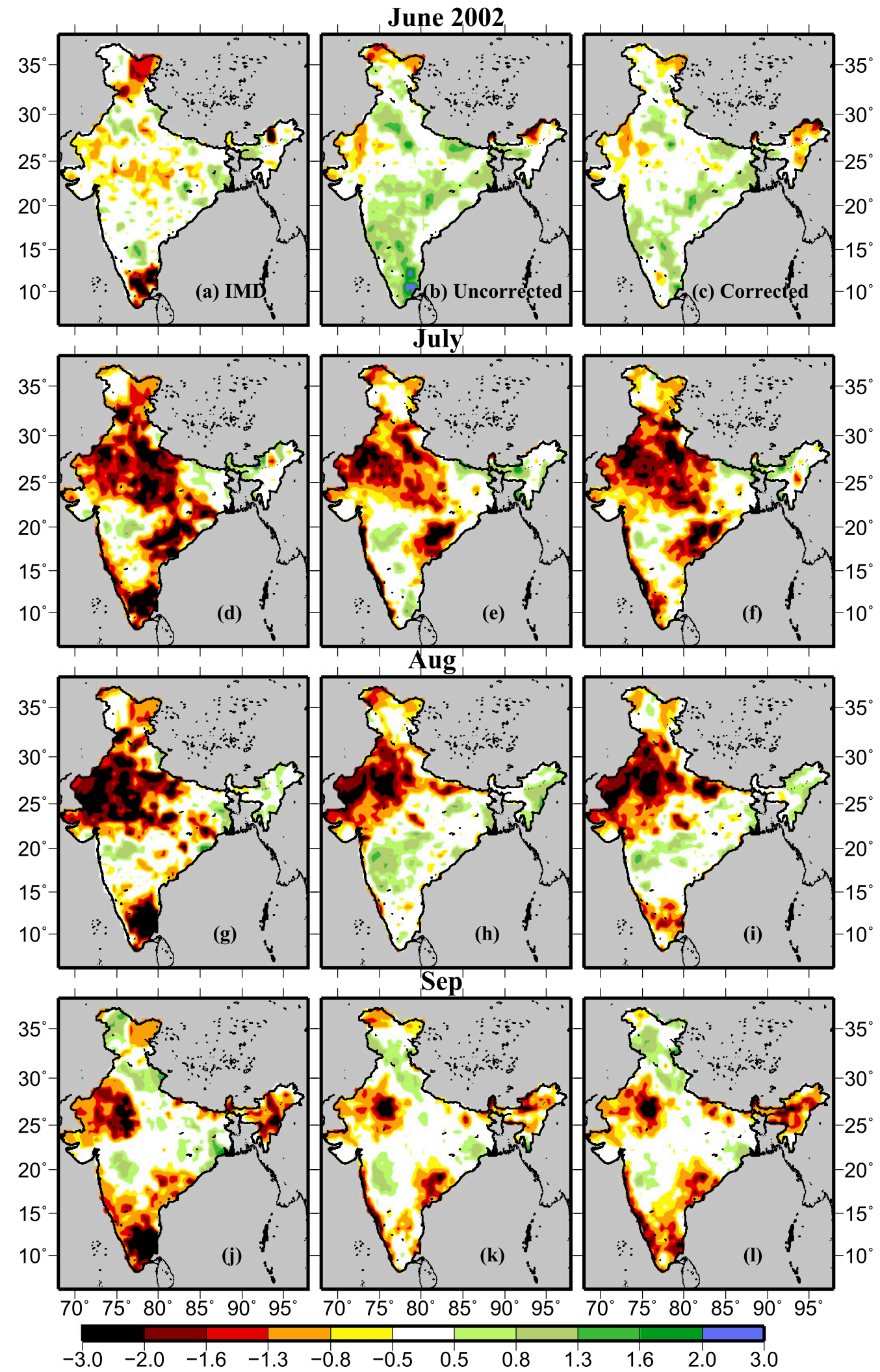

FIG. 7. The monsoon season (JJAS) soil moisture drought (based on SSI) simulated for the year 2002 using the (left) observed forcing from IMD and (middle) uncorrected and (right) corrected forcing from TRMM and GEFS. Climatological data were obtained from the IMD for the period of 1970-97. 

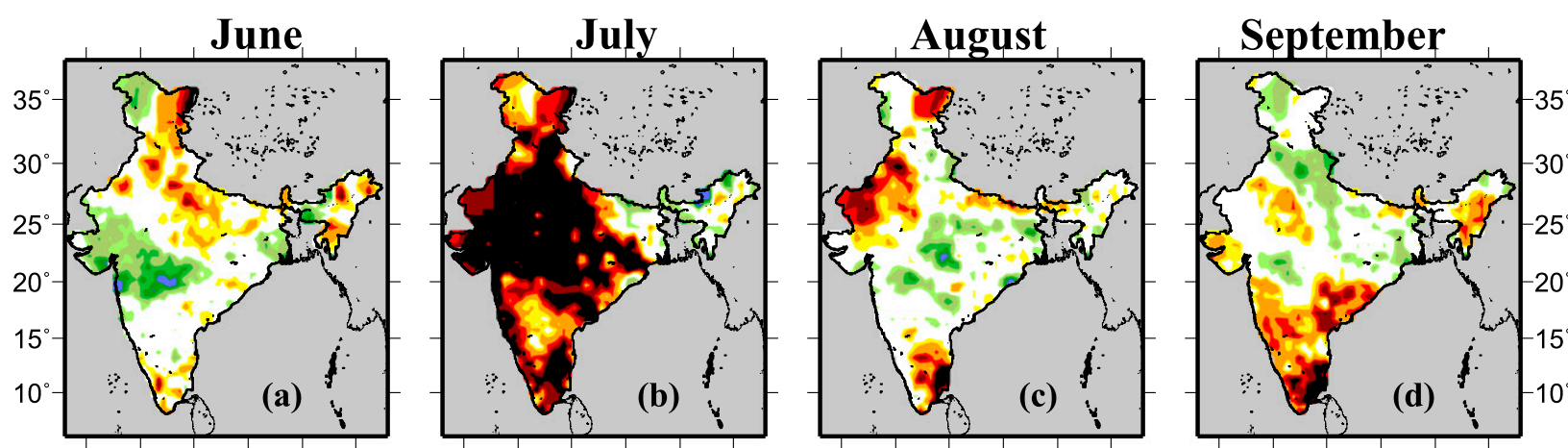

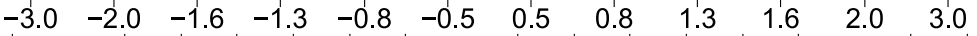
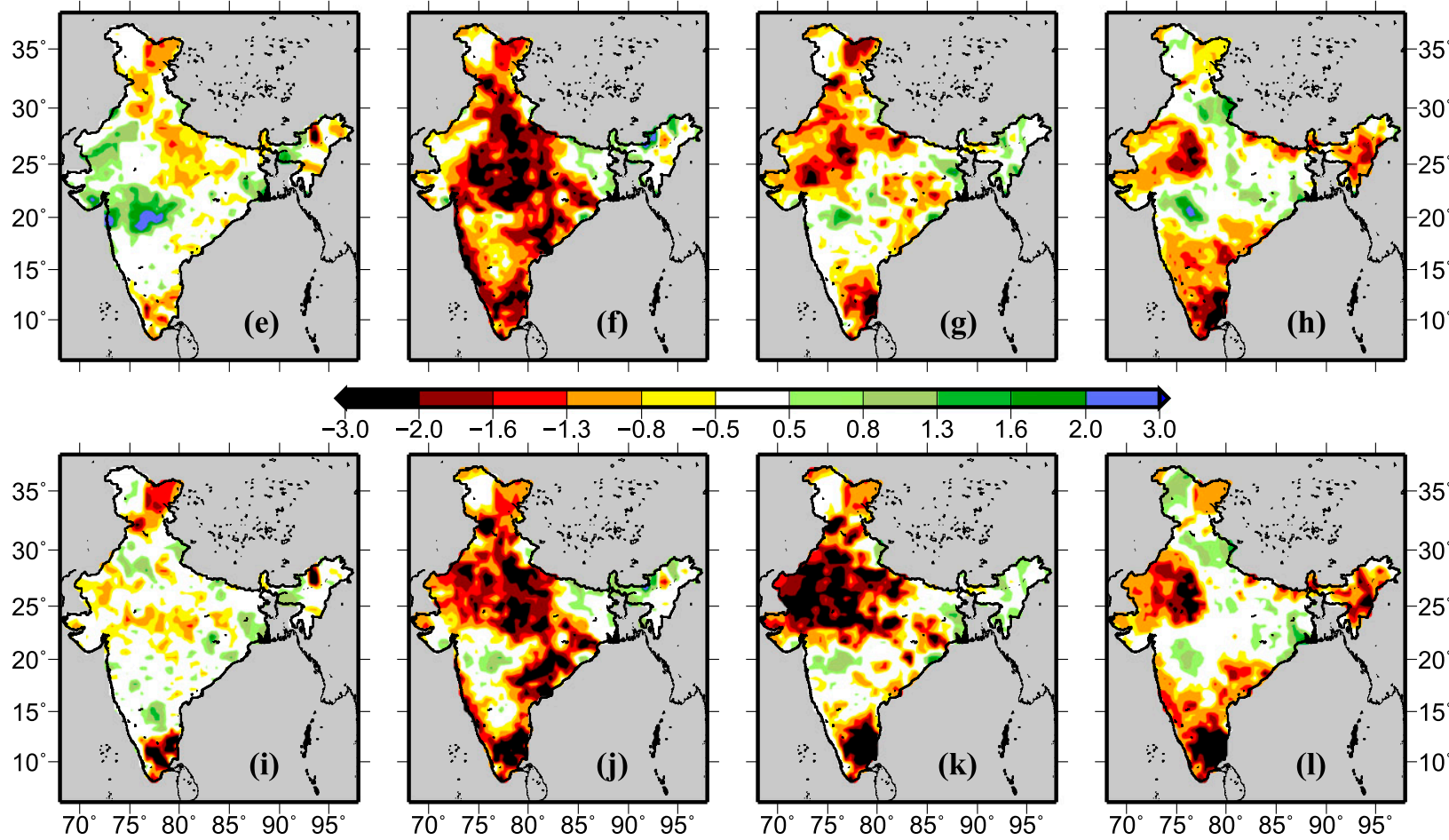

$\begin{array}{llllllllllll}3.0 & -2.0 & -1.6 & -1.3 & -0.8 & -0.5 & 0.5 & 0.8 & 1.3 & 1.6 & 2.0 & 3.0\end{array}$
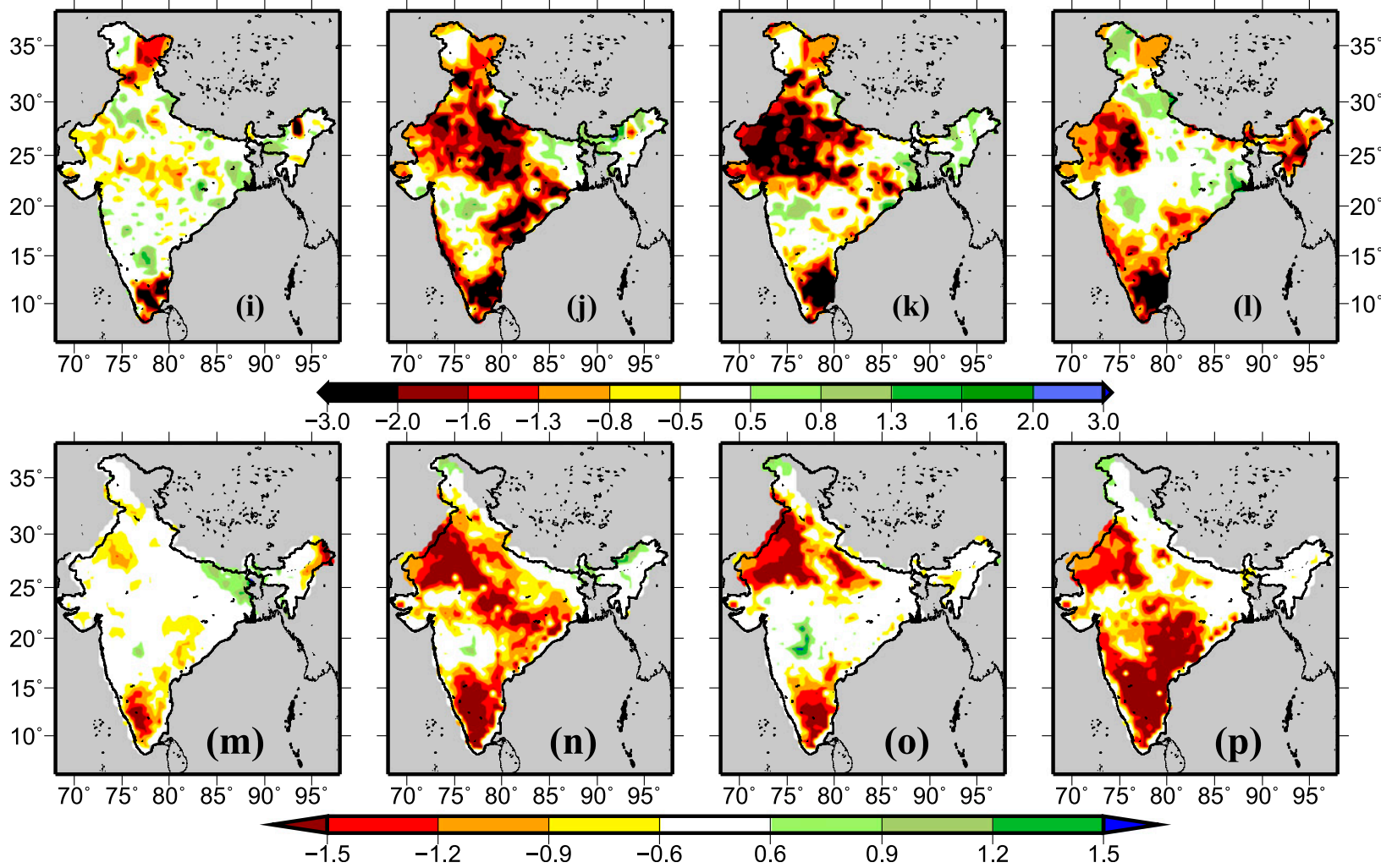

FIG. 8. Comparison of drought indices from the experimental drought monitor against the DSI for the monsoon season drought in 2002. Meteorological drought estimated using (a)-(d) SPI, (e)-(h) SRI, (i)-(1) SSI, and (m)-(p) DSI. Climatological data were obtained from the merged indices (IMD and TRMM) for the period of 1970-2010. 

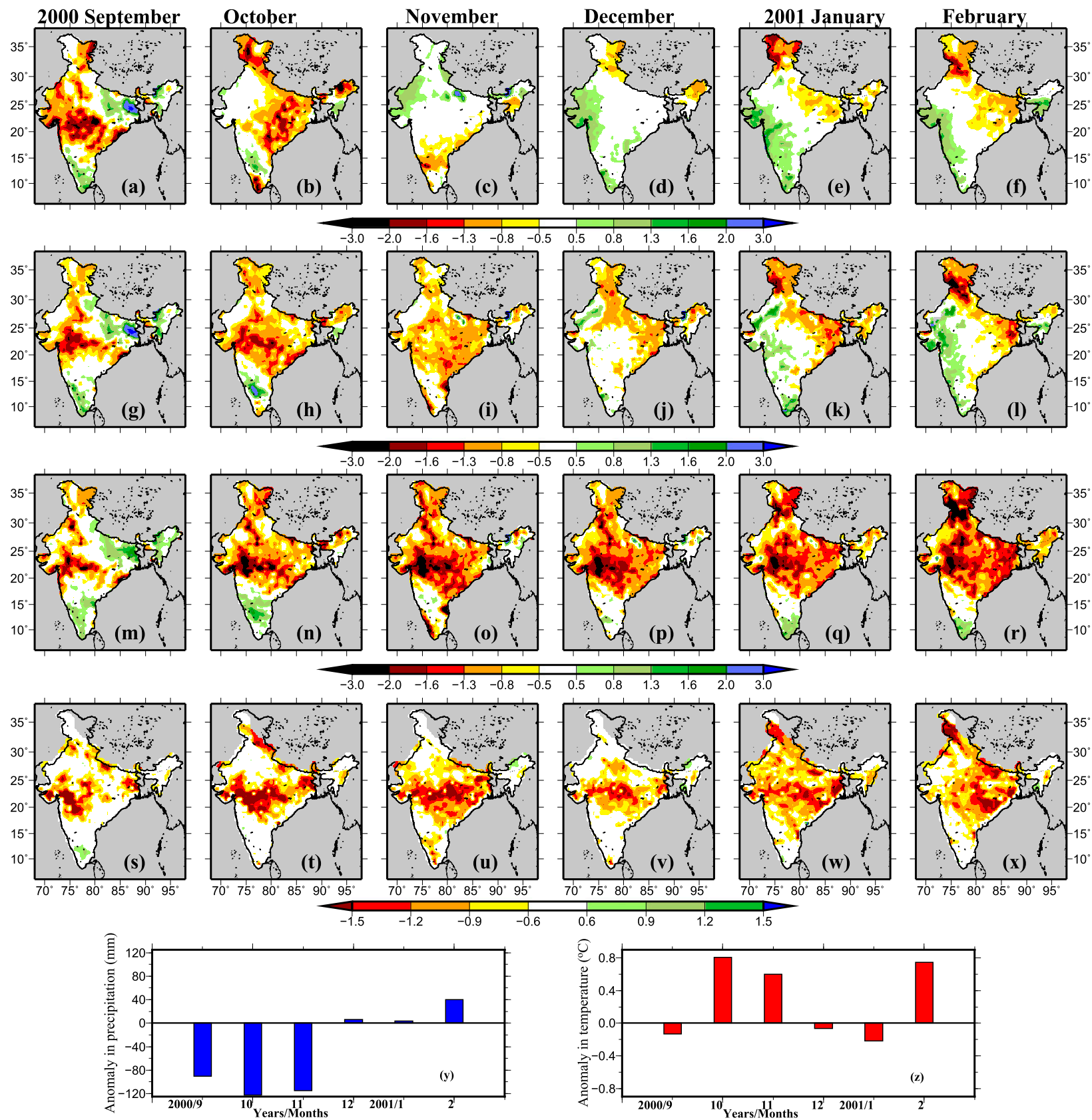

FIG. 9. Comparison of (a)-(f) SPI, (g)-(l) SRI, (m)-(r) SSI, and (s)-(x) DSI from September 2000 to February 2001. Droughts were estimated at the end of each of the selected months using a 1-month period. (y),(z) Monthly precipitation and temperature anomalies from September 2000 to February 2001.

associated with the time period that vegetation takes to respond to atmospheric forcings and (especially in northwestern India) that is not simulated in the VIC model. Moreover, irrigation mainly driven by groundwater wells during the droughts may be attributed to disparities in DSI and SSI. Overall, the VIC-simulated drought extents captured the location and intensity of droughts well.
We compared areal extents of droughts based on SPI, SRI, and SSI from October 2000 to February 2001 (Fig. 9). We were also interested in testing the performance of the experimental drought monitor during the nonmonsoon months. While meteorological drought was located in the central western and eastern regions during September and October 2000, hydrological and agricultural droughts persisted for the entire duration 

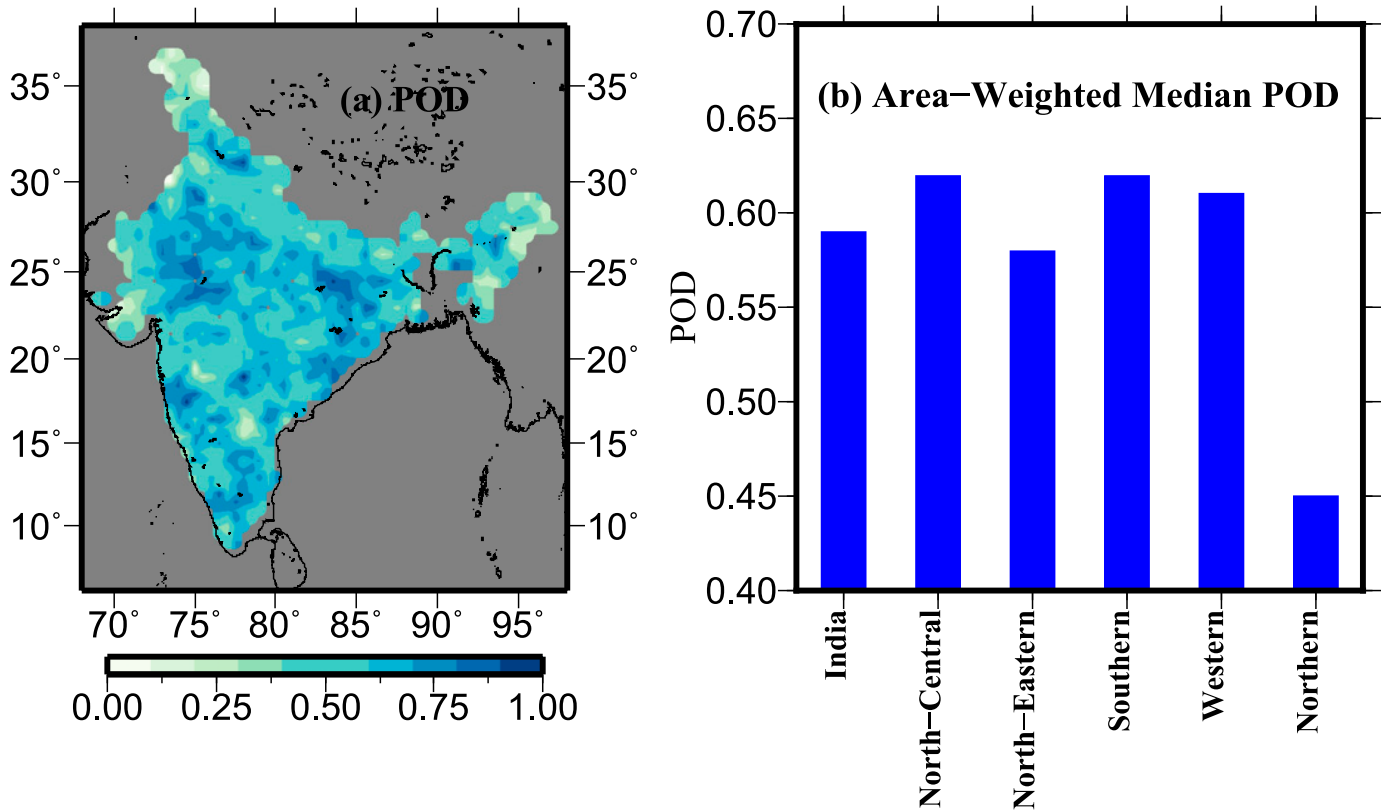

FIG. 10. (a) POD of drought (SSI < -0.6) estimated using VIC-simulated SM-60 with reference to DSI $(<-0.6)$.

(b) Area-weighted median POD in different regions.

(from October 2000 to February 2001). Moreover, in contrast to meteorological and hydrological droughts, droughts based on SSI did not recover during the December-February period, which once again underscores the need of a soil moisture-based monitoring system. We further notice that soil moisture-based drought extents showed a better relationship with a satellite-based drought index (Mu et al. 2013) highlighting linkages of SSI, with soil moisture-based stress induced in vegetation. The persistence of hydrological and agricultural droughts was driven by the above-normal temperature during the winter (Fig. 9z).

We evaluated the ability of the VIC model-simulated SSI to capture droughts against satellite-derived DSI using probability of detection (POD; Wilks 2011; AghaKouchak et al. 2011). For the period of 2000-10, POD was estimated as the ratio of months when both DSI and SSI exhibited drought $(<-0.6)$ against months when DSI showed drought (Fig. 10). We notice that POD is larger than 0.5 in $78 \%$ of grid cells, while all-India median POD was 0.59 . These results indicate that the experimental drought monitor can capture droughts in a satisfactory manner. The lowest areaweighted median POD was observed in northern India, which can be attributed to snow cover, sparse observatories, and algorithms used to derive DSI. For instance, $\mathrm{Mu}$ et al. (2013) found a lower correlation between DSI and PDSI in the tropics where frequent cloud cover and aerosols hinder remote sensing. The inconsistency between two indices can be also attributed to response time of vegetation to soil moisture. Uncertainties in DSI can be also due to coarser reanalysis forcings used in the Moderate Resolution Imaging Spectroradiometer (MODIS) evapotranspiration-potential evapotranspiration algorithm (Zhao et al. 2006), which may not resolve local cloud convection.

\section{g. District-level drought monitoring}

We divided India into five regions-western, northern, northeastern, north-central, and southern-to provide district-level drought information in real time (Fig. 11). This is particularly important as district-level administration often makes decisions on providing relief to drought-affected regions. The experimental drought monitor can successfully provide near-real-time information on drought conditions for any district in India. For instance, drought based on SSI can show a droughthit district in the southern region on 21 January 2014 (Fig. 11). The information delivered through the drought monitor can help farmers, administrators, and water managers to make timely decisions and to minimize losses caused by droughts.

\section{Conclusions}

We discussed development of the experimental nearreal-time drought monitor for India, which provides drought-related information at high spatial and temporal resolutions in near-real time. One of the major impediments to have more realistic monitoring of real-time 

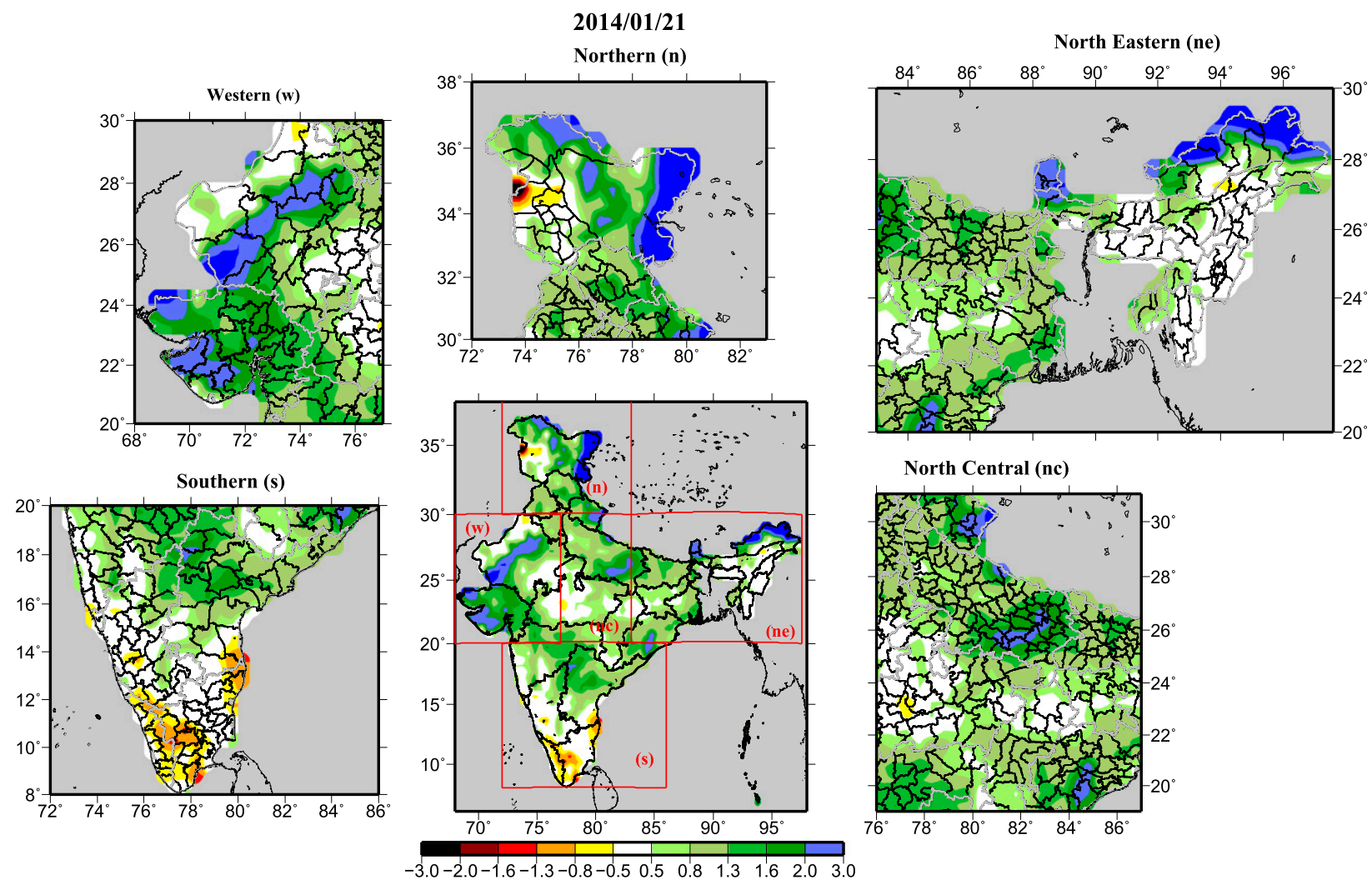

FIG. 11. District-level drought monitoring using the experimental drought monitor for India.

drought is to have long-term meteorological forcing (for defining climatology) extending up to real time (AghaKouchak and Nakhjiri 2012). We successfully developed a long-term climatology that can be used to correct real-time data for drought monitoring in India. Moreover, drought estimations from the experimental drought monitor showed promising skill against the satellite-based DSI (Mu et al. 2013). The experimental drought monitor is a unique effort as it provides highresolution information on drought in India. Moreover, the drought monitor is based on observed data from IMD forcings.

TRMM overestimated precipitation, especially for extreme events, while it underestimated the number of rainy days between 1998 and 2007 compared to the IMD dataset. Minimum and maximum temperatures from the GEFS showed a cold bias in northern India and a warm bias in northwestern and central India during the period of 1985-2003. A bias-correction approach based on monthly scale factors successfully improved bias in the TRMM and GEFS datasets.

Droughts were well simulated using the bias-corrected forcings from TRMM and GEFS. Moreover, drought extents and severity obtained using the experimental drought monitors were well compared with those obtained from the satellite-based DSI. The 2002 monsoon season and 2000-01 nonmonsoon season droughts based on SSI were in good agreement with DSI for the same period.

The experimental drought monitor provides highresolution (district level) drought information on a daily basis that can be used for planning and decision making. Uncertainty in station-based gridded and satellite-based (or model based) precipitation and temperature data are sources of errors in the drought monitor. Bias correction is inevitable to normalize uncertainty among reconstructed datasets to reduce the error in drought monitoring, as shown by the results. Longer records of satellite-based precipitation will help to improve the bias-correction approach. Moreover, the availability of updated observed station data will enhance the capacity of the system after successful calibration and evaluation. The drought monitor currently considers droughts due to atmospheric forcing only; the effects of natural or artificial reservoirs, irrigation, and other management practices are not incorporated. The experimental drought monitor (located at https://sites. google.com/a/iitgn.ac.in/india_drought_monitor/home) provides near-real-time information on hydrological, agricultural, and meteorological droughts at high spatial and temporal resolutions. 
Acknowledgments. The authors acknowledge support from the Varahmihir Fellowship from the Indian Ministry of Earth Sciences to the second author. The fellowship from the Indian Ministry of Human Resources Department to the first author is greatly appreciated. The work is undertaken as part of the ITRA Media Lab Asia project entitled "Measurement to Management (M2M): Improved Water Use Efficiency and Agricultural Productivity through Experimental Sensor Network."

\section{REFERENCES}

AghaKouchak, A., and N. Nakhjiri, 2012: A near real-time satellitebased global drought climate record. Environ. Res. Lett., 7, 044037, doi:10.1088/1748-9326/7/4/044037.

-, A. Behrangi, S. Sorooshian, K. Hsu, and E. Amitai, 2011: Evaluation of satellite-retrieved extreme precipitation rates across the central United States. J. Geophys. Res., 116, D02115, doi:10.1029/2010JD014741.

— A. Mehra, A. Norouzi, and A. Behrangi, 2012: Systematic and random errors components in satellite precipitation data sets. Geophys. Res. Lett., 39, L09406, doi:10.1029/ 2012GL051592.

Andermann, C., S. Bonnet, and R. Gloaguen, 2011: Evaluation of precipitation data sets along the Himalayan front. Geochem. Geophys. Geosyst., 12, Q07023, doi:10.1029/2011GC003513.

Andreadis, K. M., and D. P. Lettenmaier, 2006: Trends in 20th century drought over the continental United States. Geophys. Res. Lett., 33, L10403, doi:10.1029/2006GL025711.

_ E. A. Clark, A. W. Wood, A. F. Hamlet, and D. P. Lettenmaier, 2005: Twentieth-century drought in the conterminous United States. J. Hydrometeor., 6, 985-1001, doi:10.1175/JHM450.1.

Bollasina, M. A., Y. Ming, and V. Ramaswamy, 2011: Anthropogenic aerosols and the weakening of the South Asian summer monsoon. Science, 334, 502-505, doi:10.1126/science.1204994.

Chapin, F. S., III, 1991: Integrated responses of plants to stress. Bioscience, 41, 29-36, doi:10.2307/1311538.

Cherkauer, K. A., L. C. Bowling, and D. P. Lettenmaier, 2003: Variable infiltration capacity cold land process model updates. Global Planet. Change, 38, 151-159, doi:10.1016/ S0921-8181(03)00025-0.

Dahm, C. N., M. A. Baker, D. I. Moore, and J. R. Thibault, 2003: Coupled biogeochemical and hydrological responses of streams and rivers to drought. Freshwater Biol., 48, 12191231, doi:10.1046/j.1365-2427.2003.01082.x.

FAO, 2011: A severe winter drought in the North China Plain may put wheat production at risk. FAO GIEWS Special Alert 330, 4 pp. [Available online at www.fao.org/docrep/013/al975e/ a1975e00.pdf.]

Feyen, L., and R. Dankers, 2009: Impact of global warming on streamflow drought in Europe. J. Geophys. Res., 114, D17116, doi:10.1029/2008JD011438.

Gao, H., and Coauthors, 2009: Water budget record from Variable Infiltration Capacity (VIC) model. Algorithm Theoretical Basis Doc., 56 pp. [Available online at www.hydro.washington.edu/ SurfaceWaterGroup/Publications/Water_Cycle_MEaSUREs ATBD_VICmodel_submit.doc.]

Hamill, T. M., G. T. Bates, J. S. Whitaker, D. R. Murray, M. Fiorino, T. J. Galarneau Jr., Y. Zhu, and W. Lapenta, 2013: NOAA's second-generation global medium-range ensemble reforecast data set. Bull. Amer. Meteor. Soc., 94, 1553-1565, doi:10.1175/BAMS-D-12-00014.1.

Hansen, M. C., R. S. DeFries, J. R. Townshend, and R. Sohlberg, 2000: Global land cover classification at $1 \mathrm{~km}$ spatial resolution using a classification tree approach. Int. J. Remote Sens., 21, 1331-1364, doi:10.1080/014311600210209.

Hao, Z., and A. AghaKouchak, 2013: Multivariate Standardized Drought Index: A parametric multi-index model. Adv. Water Resour., 57, 12-18, doi:10.1016/j.advwatres.2013.03.009.

,,-- N. Nakhjiri, and A. Farahmanand, 2014: Global integrated drought monitoring and prediction system. Sci. Data, 1, 140001, doi:10.1038/sdata.2014.1.

Huang, Y., and Coauthors, 2013: Evaluation of version-7 TRMM Multi-Satellite Precipitation Analysis product during the Beijing extreme heavy rainfall event of 21 July 2012. Water, 6 , 32-44, doi:10.3390/w6010032.

Huffman, G. J., and Coauthors, 2007: The TRMM Multisatellite Precipitation Analysis (TMPA): Quasi-global, multiyear, combined-sensor precipitation estimates at fine scales. $J$. Hydrometeor., 8, 38-55, doi:10.1175/JHM560.1.

Jalota, S., and V. Arora, 2002: Model-based assessment of water balance components under different cropping systems in northwest India. Agric. Water Manage., 57, 75-87, doi:10.1016/ S0378-3774(02)00049-5.

Kalnay, E., and Coauthors, 1996: The NCEP/NCAR 40-Year Reanalysis Project. Bull. Amer. Meteor. Soc., 77, 437-471, doi:10.1175/1520-0477(1996)077<0437:TNYRP>2.0.CO;2.

Kanamitsu, M., 1989: Description of the NMC Global Data Assimilation and Forecast System. Wea. Forecasting, 4, 335-342, doi:10.1175/1520-0434(1989)004<0335:DOTNGD>2.0.CO;2.

Kogan, F. N., 1997: Global drought watch from space. Bull. Amer. Meteor. Soc., 78, 621-636, doi:10.1175/1520-0477(1997)078<0621: GDWFS $>2.0 . \mathrm{CO} ; 2$.

Kumar, S. V., and Coauthors, 2006: Land information system: An interoperable framework for high resolution land surface modeling. Environ. Modell. Software, 21, 1402-1415, doi:10.1016/ j.envsoft.2005.07.004.

Liang, X., 1994: Two-layer Variable Infiltration Capacity land surface representation for general circulation models. Water Resources Service TR-140, 233 pp. [Available online at http:// ntrs.nasa.gov/archive/nasa/casi.ntrs.nasa.gov/19980073396.pdf.]

_ D. D. P. Lettenmaier, and E. F. Wood, 1996: One-dimensional statistical dynamic representation of subgrid spatial variability of precipitation in the two-layer variable infiltration capacity model. J. Geophys. Res., 101, 21403-21421, doi:10.1029/ 96JD01448.

Maurer, E. P., A. W. Wood, J. C. Adam, D. P. Lettenmaier, and B. Nijssen, 2002: A long-term hydrologically based dataset of land surface fluxes and states for the conterminous United States. J. Climate, 15, 3237-3251, doi:10.1175/ 1520-0442(2002)015<3237:ALTHBD>2.0.CO;2.

McKee, T. B., N. J. Doesken, and J. Kleist, 1993: The relationship of drought frequency and duration to time scales. Proc. 8th Conf. on Applied Climatology, Anaheim, CA, Amer. Meteor. Soc., 179-183.

Mehran, A., and A. AghaKouchak, 2014: Capabilities of satellite precipitation datasets to estimate heavy precipitation rates at different temporal accumulations. Hydrol. Processes, 28, 2262-2270, doi:10.1002/hyp.9779.

Mishra, A. K., and V. P. Singh, 2010: A review of drought concepts. J. Hydrol., 391, 202-216, doi:10.1016/j.jhydrol.2010.07.012

Mishra, V., and K. A. Cherkauer, 2010: Retrospective droughts in the crop growing season: Implications to corn and soybean 
yield in the midwestern United States. Agric. For. Meteor., 150, 1030-1045, doi:10.1016/j.agrformet.2010.04.002.

- — - and S. Shukla, 2010: Assessment of drought due to historic climate variability and projected future climate change in the midwestern United States. J. Hydrometeor., 11, 46-68, doi:10.1175/2009JHM1156.1.

— B. B. Smoliak, D. P. Lettenmaier, and J. M. Wallace, 2012: A prominent pattern of year-to-year variability in Indian summer monsoon rainfall. Proc. Natl. Acad. Sci. USA, 109, 72137217, doi:10.1073/pnas.1119150109.

—, R. Shah, and B. Thrasher, 2014: Soil moisture droughts under the retrospective and projected climate in India. J. Hydrometeor., doi:10.1175/JHM-D-13-0177.1, in press.

Mitra, A., A. K. Bohra, M. N. Rajeevan, and T. N. Krishnamurti, 2009: Daily Indian precipitation analysis formed from a merge of rain-gauge data with the TRMM TMPA satellite-derived rainfall estimates. J. Meteor. Soc. Japan, 87A, 265-279, doi:10.2151/jmsj.87A.265.

Mu, Q., M. Zhao, J. S. Kimball, N. G. McDowell, and S. W. Running, 2013: A remotely sensed global terrestrial drought severity index. Bull. Amer. Meteor. Soc., 94, 83-98, doi:10.1175/ BAMS-D-11-00213.1.

Nesbitt, S., and A. Anders, 2009: Very high resolution precipitation climatologies from the tropical rainfall measuring mission precipitation radar. Geophys. Res. Lett., 36, L15815, doi:10.1029/2009GL038026.

Nijssen, B., R. Schnur, and D. P. Lettenmaier, 2001: Global retrospective estimation of soil moisture using the variable infiltration capacity land surface model, 1980-93. J. Climate, 14, 1790-1808, doi:10.1175/1520-0442(2001)014<1790:GREOSM>2.0.CO;2.

Niranjan Kumar, K., M. Rajeevan, D. S. Pai, A. K. Srivastava, and B. Preethi, 2013: On the observed variability of monsoon droughts over India. Wea. Climate Extremes, 1, 42-50, doi:10.1016/j.wace.2013.07.006.

Obasi, G. O. P., 1994: WMO's role in the international decade for natural disaster reduction. Bull. Amer. Meteor. Soc., 75, 16551661, doi:10.1175/1520-0477(1994)075<1655:WRITID>2.0.CO;2.

Panda, D. K., A. Mishra, S. K. Jena, B. K. James, and A. Kumar, 2007: The influence of drought and anthropogenic effects on groundwater levels in Orissa, India. J. Hydrol., 343, 140-153, doi:10.1016/j.jhydrol.2007.06.007.

Pozzi, W., and Coauthors, 2013: Toward global drought early warning capability: Expanding international cooperation for the development of a framework for monitoring and forecasting. Bull. Amer. Meteor. Soc., 94, 776-785, doi:10.1175/ BAMS-D-11-00176.1.

Rodell, M., and Coauthors, 2004: The Global Land Data Assimilation System. Bull. Amer. Meteor. Soc., 85, 381-394, doi:10.1175/BAMS-85-3-381.

Shah, R., and V. Mishra, 2014: Evaluation of the reanalysis products for the monsoon season droughts in India. J. Hydrometeor., 15, 1575-1591, doi:10.1175/JHM-D-13-0103.1.

Sheffield, J., and E. F. Wood, 2008a: Projected changes in drought occurrence under future global warming from multi-model, multi-scenario, IPCC AR4 simulations. Climate Dyn., 31, 79105, doi:10.1007/s00382-007-0340-z.
— and - 2008b: Global trends and variability in soil moisture and drought characteristics, 1950-2000, from observationdriven simulations of the terrestrial hydrologic cycle. J. Climate, 21, 432-458, doi:10.1175/2007JCLI1822.1.

_ - G. Goteti, F. Wen, and E. F. Wood, 2004: A simulated soil moisture based drought analysis for the United States. J. Geophys. Res., 109, D24108, doi:10.1029/2004JD005182.

Shepard, D., 1968: A two-dimensional interpolation function for irregularly spaced data. Proc. 23rd ACM National Conf., New York, NY, Association for Computing Machinery, 517-524.

Shukla, S., and A. W. Wood, 2008: Use of a standardized runoff index for characterizing hydrologic drought. Geophys. Res. Lett., 35, L02405, doi:10.1029/2007GL032487.

Smith, A. B., and R. W. Katz, 2013: US billion-dollar weather and climate disasters: Data sources, trends, accuracy and biases. Nat. Hazards, 67, 387-410, doi:10.1007/s11069-013-0566-5.

Sorooshian, S., and Coauthors, 2011: Advancing the remote sensing of precipitation. Bull. Amer. Meteor. Soc., 92, 1271-1272, doi:10.1175/BAMS-D-11-00116.1.

Srivastava, A. K., M. Rajeevan, and S. R. Kshirsagar, 2009: Development of a high resolution daily gridded temperature data set (1969-2005) for the Indian region. Atmos. Sci. Lett., 10, 249-254, doi:10.1002/asl.232.

Su, F., Y. Hong, and D. P. Lettenmaier, 2008: Evaluation of TRMM Multisatellite Precipitation Analysis (TMPA) and its utility in hydrologic prediction in the La Plata basin. J. Hydrometeor., 9, 622-640, doi:10.1175/2007JHM944.1.

Svoboda, M., and Coauthors, 2002: The Drought Monitor. Bull. Amer. Meteor. Soc., 83, 1181-1190.

Tian, Y., and C. Peters-Lidard, 2010: A global map of uncertainties in satellite-based precipitation measurements. Geophys. Res. Lett., 37, L24407, doi:10.1029/2010GL046008.

, ——, and J. Eylander, 2010: Real-time bias reduction for satellitebased precipitation estimates. J. Hydrometeor., 11, 1275-1285, doi:10.1175/2010JHM1246.1.

Wang, A., T. J. Bohn, S. P. Mahanama, R. D. Koster, and D. P. Lettenmaier, 2009: Multimodel ensemble reconstruction of drought over the continental United States. J. Climate, 22, 2694-2712, doi:10.1175/2008JCLI2586.1.

- D. P. Lettenmaier, and J. Sheffield, 2011: Soil moisture drought in China, 1950-2006. J. Climate, 24, 3257-3271, doi:10.1175/2011JCLI3733.1.

Wilks, D., 2011: Statistical Methods in the Atmospheric Sciences. 3rd ed. International Geophysics Series, Vol. 100, Academic Press, 704 pp.

Zhang, M., C. Sheng, Y. Qi, and Y. Yang, 2013: Evaluation of TRMM summer precipitation over Huai-River basin in China. Adv. Mater. Res., 726-731, 3401-3406, doi:10.4028/www.scientific.net/ AMR.726-731.3401.

Zhao, M., S. W. Running, and R. R. Nemani, 2006: Sensitivity of Moderate Resolution Imaging Spectroradiometer (MODIS) terrestrial primary production to the accuracy of meteorological reanalyses. J. Geophys. Res., 111, G01002, doi:10.1029/ 2004JG000004.

Zhao, T., and A. Yatagai, 2013: Evaluation of TRMM 3B42 product using a new gauge-based analysis of daily precipitation over China. Int. J. Climatol., 34, 2749-2762, doi:10.1002/joc.3872. 